\title{
Surveillance to Track Progress Toward Polio Eradication - Worldwide, 2018-2019
}

\begin{abstract}
Jacquelyn S. Lickness, $\mathrm{MPH}^{1}$; Tracie Gardner, $\mathrm{PhD}^{2}$; Ousmane M. Diop, $\mathrm{PhD}^{2}$; Smita Chavan, MS ${ }^{1}$; Jaume Jorba, $\mathrm{PhD}^{3}$; Jamal Ahmed, MD²; Nicksy Gumede, $\mathrm{PhD}^{4}$; Ticha Johnson, MD ${ }^{4}$; Obaid Butt, MD ${ }^{5}$; Humayun Asghar, MD ${ }^{5}$; Eugene Saxentoff, PhD ${ }^{6}$; Varja Grabovac, MSc ${ }^{7}$; Tigran Avagyan, $\mathrm{MD}^{7}$; Sudhir Joshi, $\mathrm{MPH}^{8}$; Gloria Rey-Benito, MSc ${ }^{9}$; Jane Iber, MSc 3 ; Elizabeth Henderson ${ }^{3}$; Steven G.F. Wassilak, MD ${ }^{1}$; Abhijeet Anand, MBBS ${ }^{1}$
\end{abstract}

Since the Global Polio Eradication Initiative (GPEI) was launched in 1988, the number of polio cases worldwide has declined approximately $99.99 \%$; only two countries (Afghanistan and Pakistan) have never interrupted wild poliovirus (WPV) transmission (1). The primary means of detecting poliovirus circulation is through surveillance for acute flaccid paralysis (AFP) among children aged $<15$ years with testing of stool specimens for WPV and vaccine-derived polioviruses (VDPVs) (genetically reverted strains of the vaccine virus that regain neurovirulence) in World Health Organization (WHO)-accredited laboratories $(2,3)$. In many locations, AFP surveillance is supplemented by environmental surveillance, the regular collection and testing of sewage to provide awareness of the extent and duration of poliovirus circulation (3). This report presents 2018-2019 poliovirus surveillance data, focusing on 40 priority countries* with WPV or VDPV outbreaks or at high risk for importation because of their proximity to a country with an outbreak. The number of priority countries rose from 31 in 2018 to 40 in 2019 because of a substantial increase in the number of VDPV outbreaks ${ }^{\dagger}(2,4)$. In areas with low poliovirus immunity, VDPVs can circulate in the community and cause outbreaks of paralysis; these are known as circulating vaccine derived polioviruses (cVDPVs) (4). In 2019, only 25 (63\%) of the 40 designated priority countries met AFP surveillance indicators nationally; subnational surveillance performance varied widely and indicated focal weaknesses. High

\footnotetext{
*2019 priority countries: African Region: Angola, Benin, Botswana, Burkina Faso, Burundi, Cameroon, Central African Republic, Chad, Congo, Côte d'Ivoire, Democratic Republic of the Congo, Eritrea, Ethiopia, Ghana, Guinea, Kenya, Liberia, Malawi, Mali, Mozambique, Namibia, Niger, Nigeria, Rwanda, South Sudan, Tanzania, Togo, Uganda, Zambia, and Zimbabwe; Eastern Mediterranean Region: Afghanistan, Djibouti, Pakistan, Somalia, and Sudan; South-East Asia Region: Burma (Myanmar) and Indonesia; Western Pacific Region: Malaysia, Papua New Guinea, and Philippines; 2018 priority countries; African Region: Burkina Faso, Burundi, Cameroon, Central African Republic, Chad, Democratic Republic of the Congo, Equatorial Guinea, Ethiopia, Guinea, Guinea Bissau, Kenya, Liberia, Mali, Mozambique, Niger, Nigeria, Sierra Leone, and South Sudan; Eastern Mediterranean Region: Afghanistan, Djibouti, Iraq, Jordan, Lebanon, Libya, Pakistan, Somalia, Sudan, Syria, and Yemen; South-East Asia Region: Indonesia; Western Pacific Region: Papua New Guinea.

$\dagger$ Countries were selected for the previous 2017-2018 MMWR report according to the Global Polio Surveillance Action Plan high-priority country list; countries for this report (2018-2019) were selected according to whether they had endemic transmission, had a VDPV outbreak, or were in geographic proximity to an outbreak in Africa.
}

quality, sensitive surveillance is important to ensure timely detection and response to cVDPV and WPV transmission.

\section{Acute Flaccid Paralysis Surveillance}

Two primary surveillance performance indicators assess AFP surveillance quality. The first is the nonpolio AFP (NPAFP) rate $^{\S}$ (the number of NPAFP cases per 100,000 children aged $<15$ years per year); an NPAFP rate $\geq 2$ is considered sufficiently sensitive to detect circulating poliovirus. The second is the collection of adequate stool specimens from AFP patients (i.e., two stool specimens collected $\geq 24$ hours apart and within 14 days of paralysis onset) and arrival of these specimens at a WHO-accredited laboratory by reverse cold chain (storing and transporting samples at recommended temperatures from the point of collection to the laboratory) and in good condition (i.e., without leakage or desiccation) from $\geq 80 \%$ of persons with AFP, which ensures adequate sensitivity and specificity to track poliovirus circulation (3).

Among the 47 countries in the WHO African Region (AFR), the number of priority countries increased from 18 (38\%) in 2018 to $30(64 \%)$ in 2019 because of the increase in the number of VDPV outbreaks $(2,4)$. To describe the previous 2 years' performance for this year's priority countries, surveillance performance was assessed for 2018 and 2019 for the 30 2019 priority countries in AFR (Table 1). In 2018, cVDPV type 2 (cVDPV2) cases or environmental surveillance isolations were detected in five countries (Democratic Republic of the Congo [DRC], Kenya, Mozambique, Niger, and Nigeria) and, in 2019, in 14 countries (Angola, Benin, Burkina Faso, Cameroon, Central African Republic, Chad, Côte d'Ivoire, DRC, Ethiopia, Ghana, Niger, Nigeria, Togo, and Zambia). In 2018 and 2019, both the NPAFP rate and adequate stool collection AFP surveillance performance indicators were met nationally in $27(90 \%)$ and $20(67 \%)$ of the 302019 priority countries, respectively (Table 1$)$. Numerous subnational pockets of low surveillance performance were identified during 2018-2019 (Table 1) (Figure). September 2019 marked 3 years since the last reported WPV1 isolation in AFR (in Borno, Nigeria); during this period, populations living within

\footnotetext{
\$Per 100,000 children aged $<15$ years per year.
} 
TABLE 1. National and subnational acute flaccid paralysis (AFP) surveillance performance indicators and number of confirmed wild poliovirus (WPV) and circulating vaccine-derived poliovirus (cVDPV) cases, by country - 40 priority countries, World Health Organization (WHO) African, Eastern Mediterranean, South-East Asia, and Western Pacific regions, 2018-2019

\begin{tabular}{|c|c|c|c|c|c|c|c|c|}
\hline Year/WHO region/Country & $\begin{array}{c}\text { No. } \\
\text { of AFP } \\
\text { cases } \\
\text { (all ages) }\end{array}$ & $\begin{array}{c}\text { Regional/ } \\
\text { National } \\
\text { NPAFP rate }\end{array}$ & $\begin{array}{l}\text { Subnational } \\
\text { areas with } \\
\text { NPAFP } \\
\text { rate } \geq 2(\%)^{\S}\end{array}$ & $\begin{array}{c}\text { Regional or } \\
\text { national AFP } \\
\text { cases with } \\
\text { adequate } \\
\text { specimens }(\%)^{\text {q }}\end{array}$ & $\begin{array}{c}\text { Subnational } \\
\text { areas } \\
\text { with } \geq 80 \% \\
\text { adequate } \\
\text { specimens (\%) }\end{array}$ & $\begin{array}{l}\text { Population } \\
\text { living in } \\
\text { areas } \\
\text { meeting both } \\
\text { indicators }(\%)^{* *}\end{array}$ & $\begin{array}{c}\text { No. of } \\
\text { confirmed } \\
\text { WPV cases* }\end{array}$ & $\begin{array}{l}\text { No. of } \\
\text { confirmed } \\
\text { cVDPV } \\
\text { cases }^{*}+\dagger\end{array}$ \\
\hline \multicolumn{9}{|l|}{2018} \\
\hline African Region & 22,620 & 5.6 & $\mathrm{~N} / \mathrm{A}$ & 89.3 & $N / A$ & $\mathrm{~N} / \mathrm{A}$ & —§§ & 65 \\
\hline Angola & 330 & 2.3 & 77.8 & 92.7 & 94.4 & 58.8 & - & - \\
\hline Benin & 209 & 4.3 & 100.0 & 90.4 & 100.0 & 100.0 & - & - \\
\hline Botswana & 19 & 2.6 & 81.8 & 100.0 & 100.0 & 62.2 & - & - \\
\hline Burkina Faso & 359 & 4.0 & 100.0 & 85.2 & 76.9 & 83.9 & - & - \\
\hline Burundi & 122 & 2.4 & 37.5 & 90.2 & 81.3 & 27.3 & - & - \\
\hline Cameroon & 777 & 7.2 & 90.0 & 83.5 & 80.0 & 71.9 & - & - \\
\hline Central African Republic & 134 & 6.6 & 85.7 & 67.2 & 14.3 & 0.0 & - & - \\
\hline Chad & 650 & 9.0 & 100.0 & 90.5 & 81.8 & 93.8 & - & - \\
\hline Congo & 167 & 7.2 & 100.0 & 88.0 & 90.9 & 97.5 & - & - \\
\hline Côte d'Ivoire & 374 & 3.5 & 94.1 & 80.2 & 47.1 & 38.8 & - & - \\
\hline Democratic Republic of the Congo & 2,743 & 6.6 & 85.2 & 77.3 & 55.6 & 53.0 & - & 20 \\
\hline Eritrea & 114 & 5.3 & 100.0 & 95.6 & 80.0 & 96.9 & - & - \\
\hline Ethiopia & 1,079 & 2.5 & 72.7 & 83.1 & 54.5 & 51.2 & - & - \\
\hline Ghana & 510 & 4.3 & 90.0 & 87.5 & 90.0 & 75.6 & - & - \\
\hline Guinea & 232 & 4.2 & 100.0 & 88.8 & 87.5 & 81.6 & - & - \\
\hline Kenya & 680 & 3.3 & 72.3 & 87.2 & 72.3 & 56.1 & - & - \\
\hline Liberia & 72 & 3.6 & 100.0 & 84.7 & 66.7 & 81.3 & - & - \\
\hline Malawi & 210 & 2.4 & 100.0 & 88.1 & 100.0 & 100.0 & - & - \\
\hline Mali & 292 & 3.2 & 100.0 & 87.0 & 77.8 & 96.2 & - & - \\
\hline Mozambique & 463 & 3.4 & 100.0 & 88.1 & 81.8 & 86.6 & - & 1 \\
\hline Namibia & 25 & 1.8 & 66.7 & 80.0 & 66.7 & 43.3 & - & - \\
\hline Niger & 973 & 8.6 & 100.0 & 81.0 & 75.0 & 81.1 & - & 10 \\
\hline Nigeria & 9,375 & 10.9 & 100.0 & 95.3 & 100.0 & 100.0 & - & 34 \\
\hline Rwanda & 140 & 2.8 & 80.0 & 87.1 & 100.0 & 89.2 & - & - \\
\hline South Sudan & 447 & 8.3 & 100.0 & 83.0 & 60.0 & 62.9 & - & - \\
\hline Tanzania & 875 & 3.3 & 100.0 & 97.8 & 100.0 & 100.0 & - & - \\
\hline Togo & 144 & 4.4 & 100.0 & 88.2 & 100.0 & 100.0 & - & - \\
\hline Uganda & 712 & 3.3 & 62.8 & 90.4 & 88.4 & 54.8 & - & - \\
\hline Zambia & 198 & 2.4 & 66.7 & 84.3 & 66.7 & 37.1 & - & - \\
\hline Zimbabwe & 195 & 2.7 & 100.0 & 93.8 & 100.0 & 100.0 & - & - \\
\hline Eastern Mediterranean Region & 16,522 & 15.1 & N/A & 88.6 & N/A & N/A & 33 & 12 \\
\hline Afghanistan & 3,364 & 21.6 & 100.0 & 93.8 & 97.1 & 98.4 & 21 & - \\
\hline Djibouti & 0 & 0.0 & 0.0 & 0.0 & 0.0 & 0.0 & - & - \\
\hline Pakistan & 12,231 & 17.5 & 100.0 & 86.6 & 87.5 & 99.2 & 12 & - \\
\hline Somalia & 351 & 4.8 & 100.0 & 97.7 & 100.0 & 100.0 & - & 12 \\
\hline Sudan & 576 & 3.4 & 100.0 & 97.4 & 100.0 & 100.0 & - & - \\
\hline South-East Asia Region & 2,055 & 2.4 & $\mathrm{~N} / \mathrm{A}$ & 83.4 & N/A & $\mathrm{N} / \mathrm{A}$ & - & 1 \\
\hline Burma (Myanmar) & 333 & 2.4 & 76.5 & 94.3 & 100.0 & 68.6 & - & - \\
\hline Indonesia & 1,722 & 2.4 & 75.0 & 81.3 & 53.1 & 52.8 & - & 1 \\
\hline Western Pacific Region & 783 & 1.7 & $\mathrm{~N} / \mathrm{A}$ & 58.5 & $\mathrm{~N} / \mathrm{A}$ & N/A & - & 26 \\
\hline Malaysia & 170 & 2.2 & 42.9 & 79.4 & 57.1 & 23.4 & - & - \\
\hline Papua New Guinea & 285 & 7.9 & 95.5 & 43.9 & 13.6 & 7.6 & - & 26 \\
\hline Philippines & 328 & 1.0 & 0.0 & 60.4 & 0.0 & 0.0 & - & - \\
\hline
\end{tabular}

See table footnotes on the next page.

security-compromised areas in Nigeria decreased and community-based surveillance and specimen collection increased (5).

Among the 21 countries in the WHO Eastern Mediterranean Region (EMR), the number of priority countries decreased from 11 (52\%) in 2018 to five (24\%) in 2019. Surveillance performance was assessed for the five 2019 priority countries in EMR (Afghanistan, Djibouti, Pakistan, Somalia, and Sudan) for 2018 and 2019 (Table 1). From 2018 to 2019, the number of WPV1 cases increased from 21 to 29 in Afghanistan (38\% increase) and from 12 to 147 in Pakistan (1,125\% increase). In 2019, 22 cVDPV2 cases were also reported in Pakistan (Table 1). In Somalia, 12 cVDPV cases (type 2 and 3) were reported in 2018 (including one coinfection with types 2 and 3 ), and three cVDPV2 cases were reported in 2019. Four of the five EMR priority countries met both surveillance indicators in 2018 and 2019; in Djibouti only 
TABLE 1. (Continued) National and subnational acute flaccid paralysis (AFP) surveillance performance indicators and number of confirmed wild poliovirus (WPV) and circulating vaccine-derived poliovirus (cVDPV) cases, by country - 40 priority countries, World Health Organization (WHO) African, Eastern Mediterranean, South-East Asia, and Western Pacific regions, 2018-2019

\begin{tabular}{|c|c|c|c|c|c|c|c|c|}
\hline Year/WHO region/Country & $\begin{array}{c}\text { No. } \\
\text { of AFP } \\
\text { cases } \\
\text { (all ages) }\end{array}$ & $\begin{array}{c}\text { Regional/ } \\
\text { National } \\
\text { NPAFP rate }^{\dagger}\end{array}$ & $\begin{array}{l}\text { Subnational } \\
\text { areas with } \\
\text { NPAFP } \\
\text { rate } \geq 2(\%)^{\S}\end{array}$ & $\begin{array}{l}\text { Regional or } \\
\text { national AFP } \\
\text { cases with } \\
\text { adequate } \\
\text { specimens }(\%)^{\text {q }}\end{array}$ & $\begin{array}{c}\text { Subnational } \\
\text { areas } \\
\text { with } \geq 80 \% \\
\text { adequate } \\
\text { specimens (\%) }\end{array}$ & $\begin{array}{c}\text { Population } \\
\text { living in } \\
\text { areas } \\
\text { meeting both } \\
\text { indicators }(\%)^{* *}\end{array}$ & $\begin{array}{c}\text { No. of } \\
\text { confirmed } \\
\text { WPV cases* }\end{array}$ & $\begin{array}{l}\text { No. of } \\
\text { confirmed } \\
\text { cVDPV } \\
\text { cases*,†† }^{*}\end{array}$ \\
\hline \multicolumn{9}{|l|}{2019} \\
\hline African Region & 22,329 & 5.4 & $\mathrm{~N} / \mathrm{A}$ & 84.2 & $N / A$ & $\mathrm{~N} / \mathrm{A}$ & - & 287 \\
\hline Angola & 603 & 3.3 & 77.8 & 71.8 & 27.8 & 6.1 & - & 113 \\
\hline Benin & 310 & 6.1 & 100.0 & 90.6 & 84.6 & 86.5 & - & 8 \\
\hline Botswana & 27 & 3.1 & 86.7 & 66.7 & 46.7 & 32.0 & - & - \\
\hline Burkina Faso & 374 & 4.1 & 43.8 & 82.4 & 81.3 & 34.0 & - & 1 \\
\hline Burundi & 98 & 1.9 & 33.3 & 93.9 & 100.0 & 35.1 & - & - \\
\hline Cameroon & 613 & 5.7 & 80.0 & 79.8 & 50.0 & 35.9 & - & - \\
\hline Central African Republic & 230 & 8.3 & 100.0 & 51.7 & 0.0 & 0.0 & - & 21 \\
\hline Chad & 820 & 11.0 & 100.0 & 82.9 & 59.1 & 68.1 & - & 5 \\
\hline Congo & 195 & 8.1 & 100.0 & 81.0 & 58.3 & 61.9 & - & - \\
\hline Côte d'Ivoire & 421 & 3.9 & 100.0 & 77.7 & 45.0 & 42.8 & - & - \\
\hline Democratic Republic of the Congo & 3,816 & 9.0 & 92.6 & 70.6 & 7.4 & 7.2 & - & 85 \\
\hline Eritrea & 110 & 5.0 & 100.0 & 86.4 & 60.0 & 47.2 & - & - \\
\hline Ethiopia & 1,223 & 2.8 & 91.7 & 85.8 & 83.3 & 79.7 & - & 13 \\
\hline Ghana & 663 & 5.5 & 100.0 & 86.6 & 87.5 & 94.5 & - & 14 \\
\hline Guinea & 233 & 4.1 & 100.0 & 86.7 & 62.5 & 59.6 & - & - \\
\hline Kenya & 560 & 2.6 & 72.3 & 92.9 & 78.7 & 66.9 & - & - \\
\hline Liberia & 70 & 3.3 & 86.7 & 90.0 & 80.0 & 81.7 & - & - \\
\hline Malawi & 189 & 2.1 & 66.7 & 89.4 & 100.0 & 56.0 & - & - \\
\hline Mali & 301 & 3.2 & 90.9 & 82.1 & 63.6 & 77.8 & - & - \\
\hline Mozambique & 510 & 3.6 & 100.0 & 72.5 & 27.3 & 31.5 & - & - \\
\hline Namibia & 27 & 2.5 & 66.7 & 81.5 & 75.0 & 32.9 & - & - \\
\hline Niger & 906 & 7.8 & 100.0 & 67.7 & 0.0 & 0.0 & - & 1 \\
\hline Nigeria & 7,509 & 8.5 & 100.0 & 94.1 & 100.0 & 100.0 & - & 18 \\
\hline Rwanda & 125 & 2.4 & 80.0 & 89.6 & 100.0 & 89.2 & - & - \\
\hline South Sudan & 399 & 7.2 & 100.0 & 89.7 & 90.0 & 84.0 & - & - \\
\hline Tanzania & 856 & 3.1 & 96.8 & 91.8 & 100.0 & 94.1 & - & - \\
\hline Togo & 164 & 4.5 & 100.0 & 68.9 & 50.0 & 52.2 & - & 6 \\
\hline Uganda & 580 & 2.7 & 86.7 & 89.7 & 93.3 & 77.4 & - & - \\
\hline Zambia & 232 & 2.8 & 70.0 & 81.9 & 70.0 & 36.8 & - & 2 \\
\hline Zimbabwe & 165 & 2.2 & 90.0 & 83.6 & 60.0 & 57.2 & - & - \\
\hline Eastern Mediterranean Region & 19,945 & 17.8 & N/A & 88.4 & N/A & N/A & 176 & 25 \\
\hline Afghanistan & 3,768 & 23.9 & 100.0 & 94.1 & 100.0 & 100.0 & 29 & - \\
\hline Djibouti & 5 & 1.7 & 50.0 & 80.0 & 50.0 & 10.6 & - & - \\
\hline Pakistan & 15,203 & 21.2 & 100.0 & 86.5 & 100.0 & 100.0 & 147 & 22 \\
\hline Somalia & 361 & 5.0 & 100.0 & 95.6 & 100.0 & 100.0 & - & 3 \\
\hline Sudan & 608 & 3.6 & 100.0 & 96.4 & 100.0 & 100.0 & - & - \\
\hline South-East Asia Region & 2,210 & 2.6 & $\mathrm{~N} / \mathrm{A}$ & 80.5 & $\mathrm{~N} / \mathrm{A}$ & $\mathrm{N} / \mathrm{A}$ & - & 6 \\
\hline Burma (Myanmar) & 418 & 2.9 & 88.2 & 90.0 & 88.2 & 78.7 & - & 6 \\
\hline Indonesia & 1,792 & 2.5 & 72.7 & 78.3 & 54.5 & 59.5 & - & - \\
\hline Western Pacific Region & 1,279 & 2.8 & $\mathrm{~N} / \mathrm{A}$ & 55.4 & $\mathrm{~N} / \mathrm{A}$ & $\mathrm{N} / \mathrm{A}$ & - & 18 \\
\hline Malaysia & 194 & 2.5 & 78.6 & 74.7 & 50.0 & 36.2 & - & 3 \\
\hline Papua New Guinea & 213 & 7.0 & 94.4 & 76.5 & 50.0 & 43.6 & - & - \\
\hline Philippines & 872 & 2.5 & 12.5 & 46.0 & 0.0 & 0.0 & - & 15 \\
\hline
\end{tabular}

Abbreviations: N/A = not applicable; NPAFP = nonpolio AFP.

* Data as of April 2, 2020.

† Per 100,000 persons aged $<15$ years per year.

$\S$ For all subnational areas regardless of population size.

I Standard WHO target is adequate stool specimen collection from $\geq 80 \%$ of AFP cases, assessed by timeliness and condition. For this analysis, timeliness was defined as two specimens collected $\geq 24$ hours apart ( $\geq 1$ calendar day in this data set), both within 14 days of paralysis onset. Good condition was defined as arrival of specimens in a WHO-accredited laboratory with reverse cold chain maintained and without leakage or desiccation.

** Percentage of the country's population living in subnational areas that met both surveillance indicators (NPAFP rates $\geq 2$ per 100,000 persons aged $<15$ years per year and $\geq 80 \%$ of AFP cases with adequate specimens).

${ }^{+\dagger}$ CVDPV was associated with at least one case of AFP with evidence of community transmission and genetically linked. Guidelines for classification of cVDPV can be found at http://polioeradication.org/wp-content/uploads/2016/09/Reporting-and-Classification-of-VDPVs_Aug2016_EN.pdf.

$\S \S$ Dashes indicate that no confirmed cases were found.

กา For this country, MMWR uses the U.S. State Department short-form name "Burma"; WHO uses "Myanmar." 
FIGURE. Combined performance indicators for the quality of acute flaccid paralysis (AFP) surveillance* in subnational areas of 40 priority countries $^{\dagger}$ - World Health Organization (WHO) African, Eastern Mediterranean, South-East Asia, and Western Pacific regions, 2019

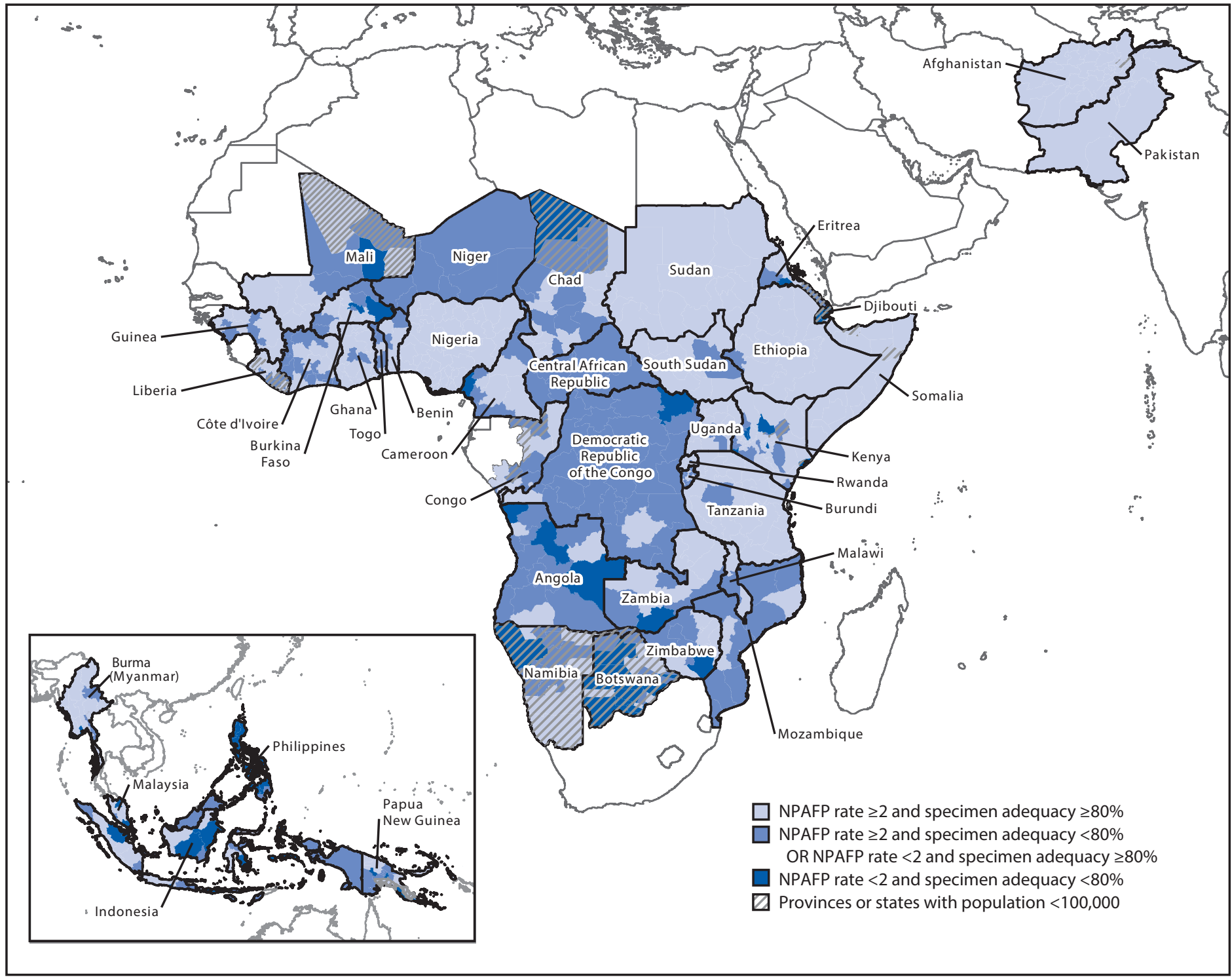

Abbreviation: NPAFP $=$ nonpolio acute flaccid paralysis.

* Targets: $\geq 2$ NPAFP cases per 100,000 children aged $<15$ years per year and $\geq 80 \%$ of persons with AFP having two stool specimens collected $\geq 24$ hours apart within

14 days of paralysis onset and arrival of these specimens at a WHO-accredited laboratory by reverse cold chain and in good condition.

† For Burma (Myanmar), MMWR uses the U.S. State Department short-form name "Burma"; WHO uses "Myanmar."

$16 \%$ of the population lived in areas meeting both indicators in 2019 (Figure).

In the Western Pacific Region (WPR), surveillance performance was assessed for three countries (Malaysia, Papua New Guinea, and Philippines) (Table 1). No priority country met both AFP surveillance indicators in 2018 and 2019. Two cVDPV type 1 (cVDPV1) cases reported in Philippines in 2019 were genetically linked to three cVDPV1 cases reported in Malaysia; 13 cVDPV2 cases were also reported in Philippines in 2019. Environmental surveillance also detected genetically linked cVDPV1 and cVDPV2 isolates in both countries. One cVDPV2 case was reported in China in 2019. Subnational NPAFP rate and stool adequacy indicators were suboptimal in Philippines and Malaysia in 2018 and 2019, indicating gaps in AFP case detection or investigation. Although Papua New Guinea met the NPAFP target performance indicator in both years, the stool adequacy target was not met at the national level.

In the South-East Asia Region (SEAR), surveillance performance was assessed for two countries (Indonesia and Burma 
[Myanmar] ) (Table 1). In 2018, both countries met both surveillance indicators and in 2019, one Burma (Myanmar) met both indicators. Six cVDPV1 cases were reported in Burma (Myanmar) in 2019, which had subnational weaknesses in NPAFP surveillance (Figure). No cVDPV1 cases were reported in Indonesia in 2019 after detection of one cVDPV1 case in 2018; however, weaknesses in subnational surveillance performance were identified in 2019.

\section{Environmental Surveillance}

Environmental surveillance enhances the sensitivity of poliovirus surveillance by identifying poliovirus circulation that might occur in the absence of detected AFP cases ( 6 ), as occurred in 2018 and 2019 in Cameroon, Côte d'Ivoire,** and Kenya; environmental surveillance confirmed cVDPV circulation well before AFP case detection in China, Central African Republic, Ghana, Malaysia, Nigeria, Philippines, and Somalia. In Iran, WPV1 was isolated from sewage in 2019 in the absence of detected AFP cases.

In Nigeria, environmental surveillance resulted in 45 cVDPV2 isolates in 2018 and 60 in 2019. In 2018, six WPV1 genetic clusters (isolates with $\geq 95 \%$ genetic relatedness) were detected in environmental surveillance from seven provinces in Afghanistan. In Pakistan, eight genetic clusters were detected from 28 districts in four provinces and in the Islamabad Capital Territory. In Pakistan, the number of WPV1 environmental surveillance detections increased in 2019, compared with that in 2018, with the largest increase in the Sindh province.

\section{Global Polio Laboratory Network (GPLN)}

GPLN comprises 145 poliovirus laboratories in the six WHO regions. GPLN laboratories implement standardized protocols to 1) isolate polioviruses (all laboratories); 2) conduct intratypic differentiation (ITD) to identify WPV, Sabin (oral polio vaccine) poliovirus and VDPV (134 laboratories); and 3) conduct genomic sequencing (28 laboratories). Poliovirus transmission pathways are monitored through sequence analysis of an isolate's viral capsid protein (VP1) coding region. Standard AFP timeliness indicators specify that laboratories should report $\geq 80 \%$ of poliovirus virus isolation results within 14 days of specimen receipt, $\geq 80 \%$ of ITD results within 7 days of isolate receipt, and $\geq 80 \%$ of sequencing results within 7 days of ITD result. The combined field and laboratory performance indicator is reporting of ITD results for $\geq 80 \%$ of isolates

\footnotetext{
For this country, $M M W R$ uses the U.S. State Department short-form name "Burma"; WHO uses "Myanmar."

** Côte d'Ivoire has confirmed three cVDPV2 cases in 2020 as of May 22.
}

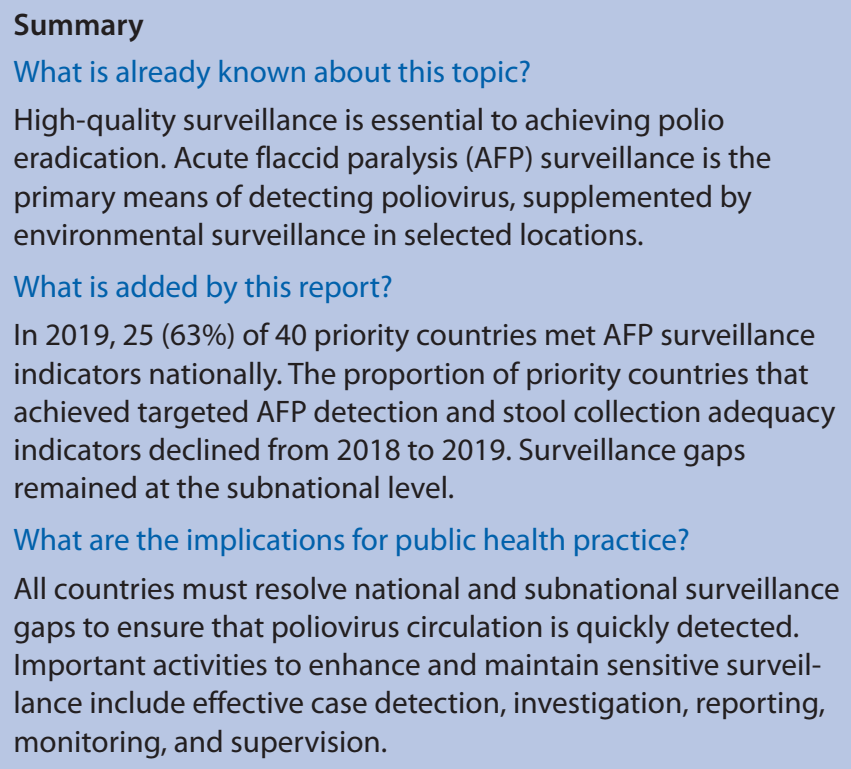
gaps to ensure that poliovirus circulation is quickly detected. Important activities to enhance and maintain sensitive surveillance include effective case detection, investigation, reporting, monitoring, and supervision.

within 60 days of paralysis onset in AFP cases. The accuracy and quality of testing at GPLN laboratories are monitored through an annual accreditation program of onsite reviews and proficiency testing ( 7 ). Another accreditation checklist is used for laboratories conducting environmental surveillance, with separate timeliness indicators.

GPLN tested 190,055 stool specimens in 2018 and 219,049 stool specimens in 2019 (Table 2). WPV1 was isolated from 33 stool specimens in 2018 and from 156 stool specimens in 2019. cVDPVs were isolated from 105 AFP patients in 2018 and from 437 in 2019. From 2018 to 2019, the number of stool specimens with cVDPV isolates increased from 65 to 303 (366\%) in AFR, from 13 to 50 in EMR (284\%), from one to $10(90 \%)$ in SEAR, and from 26 to $74(185 \%)$ in WPR. In 2018 and 2019, all regions met the timeliness indicator for poliovirus isolation.

In 2019, the South Asia genotype (the only WPV1 genotype circulating globally since 2016) was detected in Afghanistan and Pakistan. There were no "orphan" WPV1 isolates (those with $\leq 98.5 \%$ genetic identity in VP1, compared with other isolates) from AFP patients in 2018, and there were five in 2019 (two in Afghanistan and three in Pakistan), indicating possible gaps in AFP surveillance. The genetic diversity of WPV1 isolates in Afghanistan and Pakistan increased during the reporting period because of the high level of WPV1 circulation during the low season from October to May (8). Genomic sequence analysis identified seven cVDPV2 emergences in six countries in 2018 and 39 cVDPV2 emergences in 19 countries in $2019(4,5)$. 
TABLE 2. Number of poliovirus isolates from stool specimens of persons with acute flaccid paralysis (AFP) and timing of results - World Health Organization (WHO) regions, 2018 and 2019*

\begin{tabular}{|c|c|c|c|c|c|c|c|}
\hline \multirow[b]{2}{*}{ WHO region/Year } & \multirow{2}{*}{$\begin{array}{c}\text { No. of } \\
\text { specimens }\end{array}$} & \multicolumn{3}{|c|}{ No. of poliovirus isolates } & \multirow{2}{*}{$\begin{array}{l}\% \text { of poliovirus } \\
\text { isolation on time }\end{array}$} & \multirow{2}{*}{$\begin{array}{l}\% \text { of ITD results } \\
\text { within } 7 \text { days of } \\
\text { receipt of } \\
\text { specimen }^{+\dagger}\end{array}$} & \multirow{2}{*}{$\begin{array}{l}\% \text { of ITD results } \\
\text { within } 60 \text { days of } \\
\text { paralysis onset }\end{array}$} \\
\hline & & Wild $^{\dagger}$ & Sabin $\S$ & cVDPVף & & & \\
\hline \multicolumn{8}{|l|}{ African } \\
\hline 2018 & 51,292 & 0 & 2,547 & 65 & 94 & 98 & 96 \\
\hline 2019 & 51,634 & 0 & 1,207 & 303 & 93 & 99 & 94 \\
\hline \multicolumn{8}{|l|}{ Americas } \\
\hline 2018 & 1,886 & 0 & 47 & 0 & 86 & 100 & 100 \\
\hline 2019 & 1,957 & 0 & 15 & 0 & 80 & 78 & 88 \\
\hline \multicolumn{8}{|c|}{ Eastern Mediterranean } \\
\hline 2018 & 40,419 & 33 & 1,749 & 13 & 92 & 99 & 97 \\
\hline 2019 & 58,924 & 156 & 1,927 & 50 & 92 & 99 & 92 \\
\hline \multicolumn{8}{|l|}{ European } \\
\hline 2018 & 3,274 & 0 & 71 & 0 & 84 & 92 & 62 \\
\hline 2019 & 3,295 & 0 & 52 & 0 & 83 & 100 & 87 \\
\hline \multicolumn{8}{|l|}{ South-East Asia } \\
\hline 2018 & 79,566 & 0 & 1,970 & 1 & 97 & 100 & 99 \\
\hline 2019 & 88,734 & 0 & 1,807 & 10 & 94 & 98 & 97 \\
\hline \multicolumn{8}{|l|}{ Western Pacific } \\
\hline 2018 & 13,638 & 0 & 348 & 26 & 97 & 99 & 68 \\
\hline 2019 & 14,505 & 0 & 164 & 74 & 97 & 96 & 71 \\
\hline \multicolumn{8}{|l|}{ Total $\$ \S$} \\
\hline 2018 & 190,055 & 33 & 6,732 & 105 & 95 & 99 & 95 \\
\hline 2019 & 219,049 & 312 & 5,172 & 437 & 95 & 99 & 96 \\
\hline
\end{tabular}

Abbreviations: $\mathrm{CVDPV}=$ circulating vaccine-derived poliovirus; ITD = intratypic differentiation.

* 2018 data as of March 4, 2019; 2019 data as of March 18, 2020.

† Number of AFP cases with WPV isolates.

$\S$ Either 1) concordant Sabin-like results in ITD test and VDPV screening, or 2 ) $\leq 1 \%$ VP1 nucleotide sequence difference compared with Sabin vaccine virus ( $\leq 0.6 \%$ for type 2).

I For poliovirus types 1 and 3, 10 or more VP1 nucleotide differences from the respective poliovirus; for poliovirus type 2, six or more VP1 nucleotide differences from Sabin type 2 poliovirus.

** Results reported within 14 days of receipt of specimen.

${ }^{+1}$ Results of ITD reported within 7 days of receipt of specimen.

$\S \S$ For the last three indicators, total represents weighted mean percentage of indicators from the six regions.

\section{Discussion}

Although many of the 40 priority countries evaluated met national-level AFP surveillance performance indicators, the percentage of 2019 priority countries meeting both indicators declined overall from $83 \%$ in 2018 to $63 \%$ in 2019 . Critical subnational gaps were also reported in almost all countries assessed, and the decline in the number of countries meeting the stool adequacy target from 2018 to 2019 indicates challenges in timely detection and investigation of suspected AFP cases or in specimen transport and handling. GPEI has outlined activities to enhance polio surveillance in highpriority countries (9), and the surveillance status report (10) details efforts to address current challenges; despite efforts, however, shortcomings remain in detection, investigation, reporting, and monitoring. Competing priorities, limited logistical support, and heavy workloads could all contribute to suboptimal surveillance performance. The coronavirus disease 2019 (COVID-19) pandemic might exacerbate these existing challenges and present new ones in polio immunization, surveillance, and laboratory testing activities ${ }^{\dagger \dagger}$ as a result of diminished access to health care and immunization and concerns about exposure to COVID-19 cases.

The findings in this report are subject to at least three limitations. First, matters related to security, hard-to-reach subpopulations, and other factors could affect subnational AFP surveillance indicators and limit their interpretation. Second, high NPAFP rates do not necessarily indicate highly sensitive

\footnotetext{
$\dagger \dagger$ GPEI has offered its global technical and material assets to support the coronavirus disease 2019 (COVID-19) pandemic response and has recommended that preventive and response polio supplementary immunization activities be suspended until June 1,2020, or later. AFP and environmental surveillance activities should continue as possible and according to countries' COVID-19 contexts, as should preparations for the use of the novel type 2 oral poliovirus vaccine, scheduled for introduction in select countries in mid-2020.
} 
surveillance because not all reported AFP cases meet the case definition, and some AFP cases might not be detected. Finally, the accuracy of stool specimen collection timeliness depends on whether the field investigator can elicit the actual date of paralysis onset.

High-quality AFP surveillance is critical to detecting poliovirus transmission. Important activities to enhance and maintain sensitive surveillance include effective case detection, investigation, reporting, monitoring, and supervision. Where the effects of COVID-19 are particularly devastating, efforts at the national and subnational levels should be made to restore curative health systems, preventive services, and overall infectious disease surveillance and control activities and, in the process, ensure availability of resources to enhance poliovirus surveillance and safeguard progress toward polio eradication. Continuous assessment of surveillance performance at the national and subnational levels must be undertaken to identify and promptly address gaps to achieve eradication of poliovirus worldwide.

\section{Acknowledgments}

World Health Organization (WHO) Global Polio Laboratory Network (GPLN) regional sequencing laboratories and GPLN Regional Coordinators at the WHO Regional Office for the Eastern Mediterranean, WHO Regional Office for the Americas, WHO Regional Office for Europe, WHO Regional Office for the Western Pacific, WHO Regional Office for South-East Asia, and WHO Regional Office for Africa; Staff members of the Polio Eradication Branch, Global Immunization Division, Center for Global Health, CDC; Polio and Picornavirus Laboratory Branch, Division of Viral Diseases, National Center for Immunization and Respiratory Diseases, CDC; Geospatial Research, Analysis, and Services Program, Agency for Toxic Substances and Disease Registry; and Division of Emergency Operations, Center for Preparedness and Response, CDC.

Corresponding author: Jacquelyn S. Lickness, wxx3@cdc.gov, 404-639-8039.

${ }^{1}$ Global Immunization Division, Center for Global Health, CDC; ${ }^{2}$ Polio Eradication Department, World Health Organization, Geneva, Switzerland; ${ }^{3}$ Division of Viral Diseases, National Center for Immunization and Respiratory Diseases, CDC; ${ }^{4}$ Polio Eradication Department, World Health Organization, Brazzaville, Republic of Congo; ${ }^{5}$ Polio Eradication Department, World Health Organization, Amman, Jordan; ${ }^{6}$ Polio Eradication Department, World Health Organization, Copenhagen, Denmark; ${ }^{7}$ Polio Eradication Department, World Health Organization, Manila, Philippines; ${ }^{8}$ Polio Eradication Department, World Health Organization, New Delhi, India; ${ }^{9}$ Polio Eradication Department, World Health Organization, Washington, DC.
All authors have completed and submitted the International Committee of Medical Journal Editors form for disclosure of potential conflicts of interest. No potential conflicts of interest were disclosed.

\section{References}

1. Greene SA, Ahmed J, Datta SD, et al. Progress toward polio eradicationworldwide, January 2017-March 2019. MMWR Morb Mortal Wkly Rep 2019;68:458-62. https://doi.org/10.15585/mmwr.mm6820a3

2. Patel JC, Diop OM, Gardner T, et al. Surveillance to track progress toward polio eradication-worldwide, 2017-2018. MMWR Morb Mortal Wkly Rep 2019;68:312-8. https://doi.org/10.15585/mmwr. mm6813a4

3. World Health Organization. WHO-recommended surveillance standard of poliomyelitis. Geneva, Switzerland: World Health Organization; 2018. https://www.who.int/immunization/monitoring_surveillance/burden/ vpd/WHO_SurveillanceVaccinePreventable_18_Polio_R2.pdf?ua=1

4. Alleman MM, Jorba J, Greene SA, et al. Update on vaccine-derived poliovirus outbreaks - worldwide, July 2019-February 2020. MMWR Morb Mortal Wkly Rep 2020;69:489-95. https://doi.org/10.15585/ mmwr.mm6916a1

5. Adamu US, Archer WR, Braka F, et al. Progress toward poliomyelitis eradication-Nigeria, January 2018-May 2019. MMWR Morb Mortal Wkly Rep 2019;68:642-6. https://doi.org/10.15585/mmwr.mm6829a3

6. Asghar H, Diop OM, Weldegebriel G, et al. Environmental surveillance for polioviruses in the Global Polio Eradication Initiative. J Infect Dis 2014;210(Suppl 1):S294-303. https://doi.org/10.1093/infdis/jiu384

7. Diop OM, Kew OM, de Gourville EM, Pallansch MA. The Global Polio Laboratory Network as a platform for the viral vaccine-preventable and emerging diseases laboratory networks. J Infect Dis 2017;216(Suppl_1):S299-307. https://doi.org/10.1093/infdis/jix092

8. Hsu CH, Kader M, Mahamud A, et al. Progress toward poliomyelitis eradication-Pakistan, January 2018-September 2019. MMWR Morb Mortal Wkly Rep 2019;68:1029-33. https://doi.org/10.15585/mmwr. mm6845a5

9. Global Polio Eradication Initiative. Global polio surveillance action plan, 2018-2020. Geneva, Switzerland: Global Polio Eradication Initiative; 2019. http://polioeradication.org/wp-content/uploads/2016/07/GPEIglobal-polio-surveillance-action-plan-2018-2020-EN.pdf

10. World Health Organization. Global polio surveillance status report, 2019. Geneva, Switzerland: World Health Organization; 2019. http:// polioeradication.org/wp-content/uploads/2020/02/Polio-surveillancestatus-report-2019.pdf 